\title{
Confounding bias in the association between marijuana use and testicular germ cell tumors
}

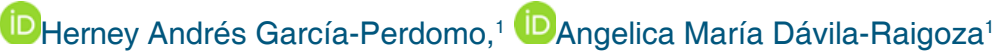

Corresponding: Herney Andrés García-Perdomo. Calle 4b \# 36-00 Email: Herney. garcia@correounivalle.edu.co Phone: $+573212195102$

\section{Dear Editor}

Regarding the manuscript written by Ghasemiesfe et al. "Association Between Marijuana Use and Risk of Cancer: A systematic review and meta-analysis" and published in the JAMA Network Open journal, we would like to make some comments. ${ }^{(1)}$

1. First, the original idea was to submit this letter to the JAMA Network Open journal but, interestingly, they do not publish letters to the editor. At any rate, the article has some critical flaws regarding the supposed association that need to be carefully analyzed, as readers will see.

2. Methodologically, there are two crucial issues: The first one is related to selection bias because the authors only included articles written in English. Despite the fact that a majority of articles are published in English, there are studies in other languages, as well. In that respect, the Cochrane manual and different organizations suggest that an excellent and well-designed systematic review must include more than one language. ${ }^{(2,3)}$ That indication could diminish selection bias. The second issue is in regard to the evaluation of the quality of the studies. The Agency for Healthcare Research and Quality utilizes the GRADE scale, which is an internationally accepted tool to assess quality of evidence and is a suggested step in carrying out any systematic review to evaluate the strength of study conclusions.

3. Regarding the statement that Marijuana use increases the risk of germ cell tumors, the authors state that they found three case-control studies that included a span of more than 10 years of marijuana use (OR, 1.36; 95\% CI, 1.03-1.81; I2 = 0\%) and the presentation of non-seminomatous testicular germ cell tumors (TGCTs) (OR, 1.85; 95\%

\footnotetext{
${ }^{1}$ Universidad del Valle. Cali, Colombia
}

Received: January 25, 2020

Accepted: January 25, 2020

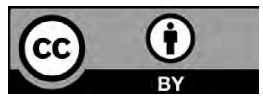




\section{Confounding bias in the association between marijuana use and testicular germ cell... García-Perdomo H.A., et al.}

CI, 1.10-3.11; I2 = 0\%). Nonetheless, germ cell tumors have genetic and anatomic factors that influence their development. Testicular dysgenesis syndrome (i.e. cryptorchidism, hypospadias, decreased spermatogenesis due to subfertility or infertility) contributes greatly to that pathology. Specifically, an undescended testis is one of the main factors associated with germ cell tumors (GCTs) (OR 2.6 to 32, according to different studies)..$^{(4,5)}$

On the other hand, an isochromosome of the short arm of chromosome 12 (12p) has been described in all histologic types of GCTs. There are also disturbances in the p53 locus and polymorphisms in the PTEN tumor suppressor gene associated with the risk of TGCT. Additionally, genome-wide association studies (GWASs) have revealed several single nucleotide polymorphisms (SNPs), in particular at 15q21.3, 2q14.2, 3q26.2, 9p24.3, $10 q 26.13,15 q 22.31$, and 19p12. ${ }^{(6,7)}$

Data on the genomic component can be challenging to find in studies, but information on location is usually described. Therefore, that should have been analyzed, given that it could be a confounding factor.

According to the information described above, we must apply those data to clinical and population settings with caution.

\section{References}

1. Ghasemiesfe M, Barrow B, Leonard S, Keyhani S, Korenstein D. Association Between Marijuana Use and Risk of Cancer: A Systematic Review and Meta-analysis. JAMA Netw Open. 2019;2(11): e1916318. doi: 10.1001/ jamanetworkopen.2019.16318

2. Higgins JPT, Green S. Cochrane Handbook for Systematic Reviews of Interventions. Version 5.1.0. John Wiley \& Sons; 2011. 659 p.

3. García-Perdomo HA. Evidence synthesis and meta-analysis: a practical approach. Int J Urol Nurs. 2016;10(1):30-6. doi: 10.1111/ijun.12087

4. Richiardi L, Pettersson A, Akre O. Genetic and environmental risk factors for testicular cancer. Int J Androl. 2007;30(4):230-40; discussion 240241. doi: 10.1111/j.1365-2605.2007.00760.x

5. Laguna MP, Wondergem N, Wink MH, Wijkstra H, Rosette J de la. Avances en el diagnostico ecográfico del cáncer de próstata. Arch Esp Urol. 2006;59(10):965-76.

6. Wang YK, Bashashati A, Anglesio MS, Cochrane DR, Grewal DS, Ha G, et al. Genomic consequences of aberrant DNA repair mechanisms stratify ovarian cancer histotypes. Nat Genet. 2017;49(6):856-65. doi: 10.1038/ ng.3849

7. Loveday C, Litchfield K, Levy M, Holroyd A, Broderick P, Kote-Jarai Z, et al. Validation of loci at 2q14.2 and 15q21.3 as risk factors for testicular cancer. Oncotarget. 2018;9(16):12630-8. doi: 10.18632/oncotarget.23117 